\title{
Adverse Health Effects Associated with Increased Activity at Kīlauea Volcano: A Repeated Population-Based Survey
}

\author{
Bernadette M. Longo \\ Division of Health Sciences, University of Nevada, Reno, NV 89557, USA \\ Correspondence should be addressed to Bernadette M. Longo; longo@unr.edu
}

Received 22 May 2013; Accepted 25 July 2013

Academic Editors: J. U. Béria, J. Spickett, and I. Szadkowska-Stanczyk

Copyright ( 2013 Bernadette M. Longo. This is an open access article distributed under the Creative Commons Attribution License, which permits unrestricted use, distribution, and reproduction in any medium, provided the original work is properly cited.

\begin{abstract}
Eruptive activity at the Kilauea volcano (Hawai'i, USA) has increased since 2008 resulting in volcanic air pollution (vog) at levels exceeding the national air quality standard for sulfur dioxide. Previous investigations during lower vog levels found adverse cardiorespiratory effects in the residents. The purpose of this 2012 survey was to reassess and compare the impact of the increased volcanic activity on population health. Prevalence of cardiorespiratory signs, symptoms, and diseases was estimated in vog exposed and unexposed communities, and descriptions of perceived health and environmental effects were collected door-to-door. Vog exposure was significantly associated with increased odds of self-reported cough, phlegm, rhinorrhea, sore/dry throat, shortness of breath, sinus congestion, continual wheezing, eye and skin irritation, and diagnosed hypertension. Field measurements identified significantly higher average systolic and diastolic blood pressures $(P=0.045,0.002)$ and lower blood oxygen saturation $(P=0.008)$. Half of the participants perceived that Kilauea's intensified eruption had negatively affected their health with reports of financial impacts from degradation of agriculture and livestock. Relatively stronger magnitudes of health effects were associated with the higher exposure to vog. Public concerns remain about attributed effects of the ongoing eruption. Enhanced public health efforts are recommended at Kilauea and other degassing volcanoes worldwide.
\end{abstract}

\section{Introduction}

Volcanic emissions have detrimental impacts on the environment and pose numerous hazards to humans. Explosive eruptions have associated mortality and adverse effects from ash fall, whereas effusive eruptions create insidious health risks from the passive degassing of emissions into the lower troposphere [1]. An estimated 9\% of the world's population live $\leq 100 \mathrm{~km}$ of a historically active volcano [2]. Therefore, it is imperative to gain an understanding of humanenvironmental interactions, identify health effects, and develop public health interventions for vulnerable populations exposed to volcanic air pollution.

Effusive eruption at the Kilauea volcano on the island of Hawai' $i$ has persisted since 1986 from various vents on the volcano's east rift zone. Emissions are predominantly water vapor mixed with carbon dioxide and sulfur dioxide $\left(\mathrm{SO}_{2}\right)$, finely-sized sulfurous particles $\left(\mathrm{PM}_{2.5}\right.$; primarily sulfuric acid aerosol), and trace gases of hydrogen sulfide, hydrogen fluoride, mercury, other halogens, and trace metals $[3,4]$. As
$\mathrm{SO}_{2}$ gas oxidizes to sulfate particles through various chemical and atmospheric processes, communities downwind of Kilauea experience exposure to volcanic smog, known as $\operatorname{vog}$ (Figure 1) [4]. Since 2008, regional air pollution has increased substantially due to an additional eruption vent at the volcano's summit crater (Figure 2). The World Health Organization (WHO) guideline [5] and National Ambient Air Quality Standard [6] for $\mathrm{SO}_{2}$ are exceeded on a near-daily basis in the downwind area; a cause of concern for public health.

The impact of Killauea's long-standing eruption has been considerable. In 1990, lava flows destroyed over 180 homes and the entire town of Kalapana, resulting in displacement of the residents. High pollution events have occurred with the new summit activity including in April 2008 when a large subdivision located $60 \mathrm{~km}$ downwind spiked $>2,000 \mathrm{ppbv}$ $\mathrm{SO}_{2}$, resulting in immediate agricultural destruction [7]. In July 2008, the federal government approved a disaster declaration for Hawai'i Island's farmers. Yet Hawai i's story is not unique. Deterioration of vegetation and agriculture due 


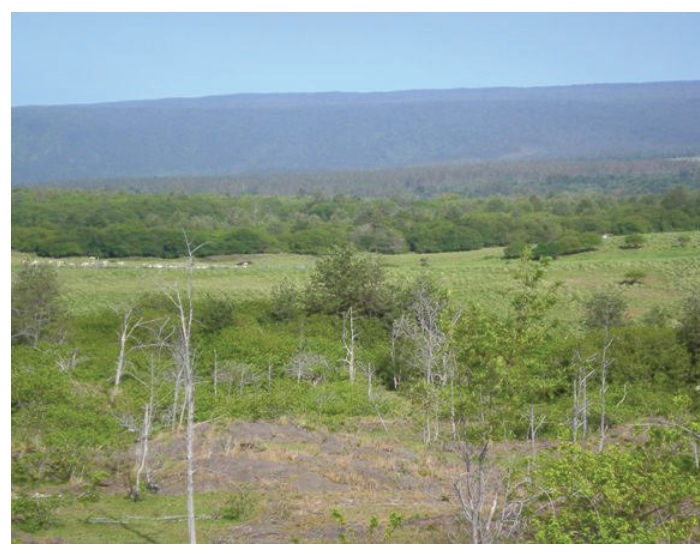

(a)

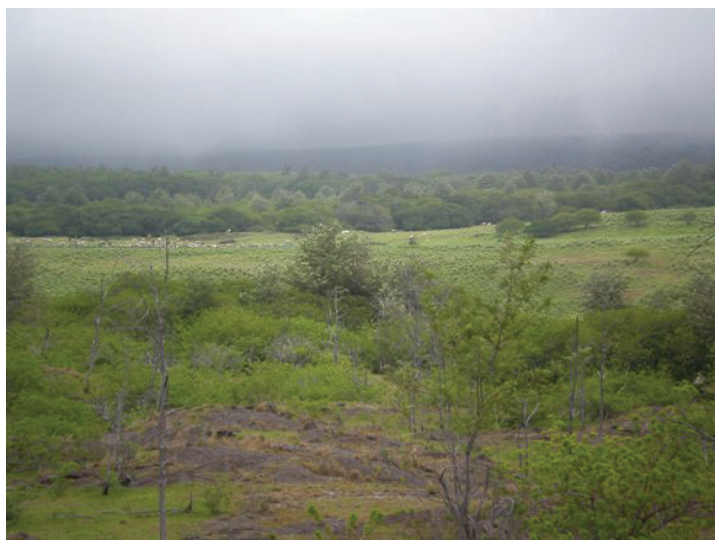

(b)

FIGURE 1: Exposure of volcanic smog "vog" in the geographic area downwind of Kîlauea.

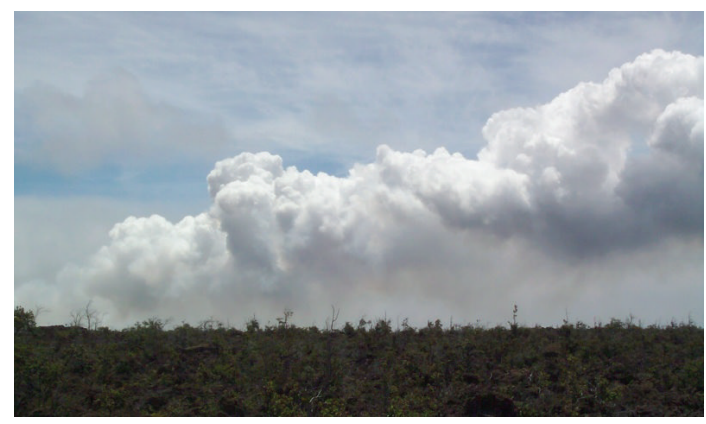

Figure 2: Emissions from Kilauea's summit showing the low-lying nature of the eruption plume.

to degassing at Masaya volcano in Nicaragua has occurred for over a century [8].

Investigations are limited on health effects associated with volcanic degassing. Consistency in these findings suggests that sulfurous volcanic emissions are associated with acute health effects and illnesses in exposed populations. The 1783 effusive eruption of Iceland's Laki volcano produced vog-like pollution over Europe, and medical records documented eye sensitivity, sore throat, cough, shortness of breath, rhinorrhea, headache, and asthma-like exacerbations in the population [9]. In 2005, workers returned to Japan's Miyakejima island after evacuation due to eruption of the island's volcano. Strong dose-response relationships were found between the $\mathrm{SO}_{2}$ degassing and symptoms of cough, sore throat, and breathlessness [10].

At Kîlauea, studies identified adverse health effects associated with low levels of vog prior to the 2008 summit eruption. In the first decade of eruption, workers at Hawai' $i$ Volcanoes National Park reported cough, phlegm, headache, eye irritation, nasal irritation, wheezing, shortness of breath, and throat irritation [11]. In 2004, an initial health survey was conducted when daily $\mathrm{SO}_{2}$ exposure averaged 25 parts per billion (ppbv). Vog-exposed residents experienced increased prevalence of cough, phlegm, rhinorrhea, sore/dry throat, sinus congestion, wheezing, eye irritation, and bronchitis compared to unexposed island residents [12]. Significant elevations in systolic blood pressure and pulse rate were also observed. In a qualitative study, vog-exposed informants noted difficulty in controlling preexisting respiratory conditions at the low exposure levels [13]. In early 2008, when Killauea's activity increased and $\mathrm{SO}_{2}$ exposure increased threefold (averaged 75 ppbv/day) from the previous months, significant associations were found between higher vog and increased outpatient clinic visits for cough, headache, pharyngitis, and acute airway problems [14]. In mid-2008, a 6-month hospital surveillance study found a significant increase in emergency department visits for broadly-defined respiratory problems within vog-exposed areas of the island [15]. Still, investigations have not assessed if the increased volcanic activity is concordant with health effects. Therefore, the purpose of this study was to reassess the health impact relative to Kilauea's increased activity and higher exposure of vog. Study objectives were to (1) determine prevalence of current cardiorespiratory symptoms and diseases from groups of vog-exposed and unexposed island residents; (2) examine differences in cardiorespiratory signs; (3) estimate the associated effect of increased exposure; and (4) compare epidemiological estimates to the initial findings from 2004.

\section{Materials and Methods}

A cross-sectional environmental-epidemiological design assessed exposure and selected the geographic study areas. Volcanic emission data for point source estimation was obtained from the Hawaiian Volcano Observatory of the US Geological Survey (USGS), and air quality data for the exposure assessment was obtained from air monitors in the study area operated by the State of Hawai'i Clean Air Branch. Study groups were selected based on geographic exposure relative to the island's wind patterns. A cross-sectional design was then used to collect health data obtained by clinical assessment from a door-to-door survey using geographic stratified sampling. The study protocol was approved by the Biomedical Institutional Review Board of the University of Nevada, Reno. The study design, sampling framework, procedures, and analyses were replicated from the initial 2004 population health survey at Kilauea [12]. The exposure level, 
geographic study locations, and participants were different, yet allowed comparison to earlier findings.

2.1. Setting and Exposure. The exposed and unexposed geographic areas were rural, with accessible health care facilities that served clients regardless of health insurance coverage. The areas were comparable in meteorology, topography, vegetation, grazing lands, and historical agriculture. No site had substantial anthropogenic air pollution. The residents shared similar histories and lived in areas of former sugar plantations where companies had constructed small towns of plantationstyle houses called camps that remained populated today. The study areas also included modern towns and residential subdivisions.

The southern region of the island was continually exposed to Kilauea's emissions due to the flow of the Pacific trade winds through the marine boundary layer and a temperature inversion at $\sim 1800 \mathrm{~m}$ above sea level. The exposed study area was selected to assess geospatial effects and ranged from the boundary of Hawaii Volcanoes National Park to $\sim 70 \mathrm{~km}$ distance from source (DFS; i.e., distance from Kïlauea's summit vent) on the southern Kona coast. The most proximal area $(\sim 30 \mathrm{~km} D F S)$ experienced a diurnal pattern of vog exposure with the highest concentrations of $\mathrm{SO}_{2}$ and $\mathrm{PM}_{2.5}$ from $7 \mathrm{pm}$ to 10 am daily; $\mathrm{SO}_{2}$ was the predominant pollutant. Downwind distal areas $(\geq 50 \mathrm{~km}$ DFS) received an inconsistent temporal pattern yet were continually exposed to relatively more sulfate $\mathrm{PM}_{2.5}$ than $\mathrm{SO}_{2}$. The unexposed area was similar in size and ranged from $40 \mathrm{~km}$ to $90 \mathrm{~km}$ DFS along the northeastern section of the island.

Environmental conditions during the 6-week study during spring of 2012 included usual northeastern Pacific trade winds without disturbances, continuous volcanic activity on the east rift zone and summit, and no lava-sea entries. Kìlauea's emissions averaged 1,340 tpd $\mathrm{SO}_{2}$, as estimated by the USGS using a FLYSPEC spectrometer [21]. Ambient air quality was assessed from state-operated fixed monitors and the researcher's portable instrument. $\mathrm{SO}_{2}$, measured continuously by a TECO pulsed-fluorescence fixed monitor, averaged $49 \mathrm{ppbv} /$ day (hourly range: $0-1,700 \mathrm{ppbv}$ ) in the exposed area and was negligible in the unexposed area. The National Ambient Air Quality Standard for $\mathrm{SO}_{2}$ was exceeded on $72 \%$ of the study days (1-hr average $\geq 75 \mathrm{ppbv}$ ) [6, 22]. WHO's 24 $\mathrm{hr} \mathrm{SO}_{2}$ guideline [5] was exceeded on $100 \%$ of the study days. Real-time $\mathrm{SO}_{2}$ measurements were obtained at each exposed participant's residence with an Interscan 4000 Series $\mathrm{SO}_{2}$ monitor and ranged from $0 \mathrm{ppbv}$ to $600 \mathrm{ppbv}$. The average 24-hr concentration of $\mathrm{PM}_{2.5}$, measured by a Met-One betaattenuation mass fixed monitor, was $6.4 \mu \mathrm{g} / \mathrm{m}^{3}$ (hourly range: $0.0-52.0 \mu \mathrm{g} / \mathrm{m}^{3}$ ) in the exposed area and $2.0 \mu \mathrm{g} / \mathrm{m}^{3}$ (hourly range: $0.0-4.0 \mu \mathrm{g} / \mathrm{m}^{3}$ ) in the unexposed area. In addition, remote sensing data were reviewed daily from the Ozone Monitoring Instrument (Figure 3) and the Moderate Resolution Imaging Spectroradiometer to confirm vog exposure and nonexposure in the reference area.

2.2. Sampling. Cross sections of each study area, proximal to distal from the volcano, were employed to obtain a geographically representative and probability-based sample. Sampling

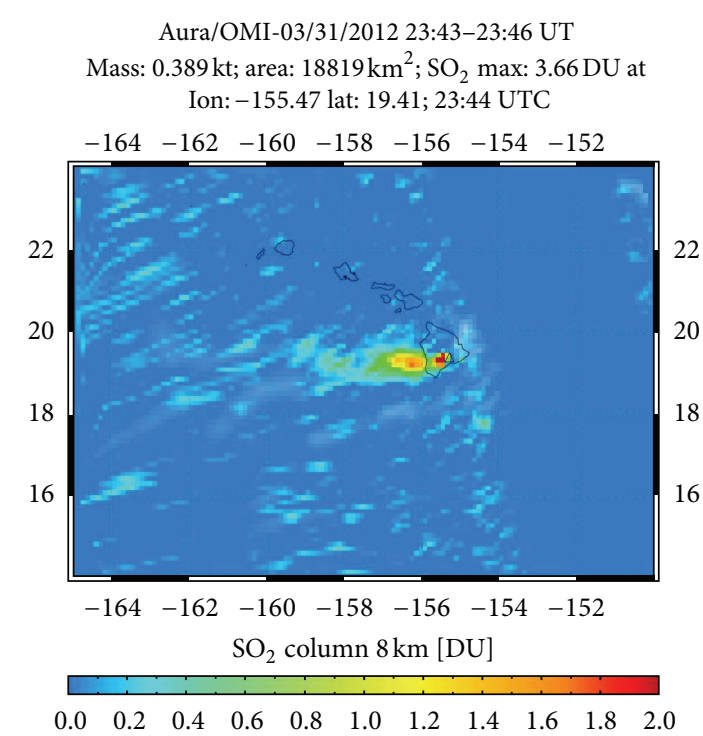

FIGURE 3: An example of daily remote sensing data used for assessing $\mathrm{SO}_{2}$ exposure in the Hawaiian Islands during the study's time frame. Credit: National Aeronautics and Space Administration, Goddard Space Flight Center, Volcanic Hazards Project.

included all towns and camps as well as residences in outlying locations. Participants were systematically selected from every 4th household on every street in towns and rural subdivisions. Sampling was restricted to no more than two participants per household to avoid over-representation of any one household. Sampling occurred during daylight hours 6 days a week. Eligible participants were adults aged $\geq 20$ years with a minimum residence of 7 years (i.e., chronic exposure). The residents of the study areas were primarily Filipinos, native Hawaiians, Japanese, Pacific islanders, and nonHispanic Whites [23]. The participation rate among eligible residents was $94 \%$.

2.3. Procedures. Verbal informed consent was obtained from all participants at the outset of their participation. Health data were collected by interview and physical assessment at participants' homes by the researcher (an advanced public health nurse) in English (94\%) or Tagalog (6\%); none were needed in Japanese translation. The health interview was comprised of standardized, yes/no questions (current cardiorespiratory and dermal symptoms; lifestyle factors and demographic data) taken from the validated National Health and Nutrition Examination Survey [24], and American Thoracic Society's Respiratory Symptom Questionnaire [25]. A health history was obtained for medically diagnosed diseases (since 2008) and current medications. Participants provided qualitative descriptions of how Kilauea's increased activity had affected their health, daily lives, and the environment.

The health assessment included blood pressure (BP), radial pulse rate, respiratory rate, and oximetry taken on all participants after 15 minutes of rest in a sitting position. BP was measured with a calibrated aneroid sphygmomanometer placed at heart level, with a proper cuff for arm size, using the slow-deflation auscultatory method [26]. For systolic 
pressures $\geq 160 \mathrm{~mm} \mathrm{Hg}$, two measurements were taken 5 minutes apart. Radial pulse rates were taken for 30 seconds with regular rhythm and 1 minute for irregular rhythms. Respiratory rate and blood oxygen saturation measured by an oximeter were assessed over a 1-minute time period. The same researcher and equipment were used with all study participants to prevent interviewer bias, minimize misclassification bias, and ensure reliability of these data. Time commitment for participants averaged 20 minutes.

2.4. Statistical Analyses. To estimate the effects of vog exposure, crude odds ratios (ORs) were calculated from prevalence estimates for each exposure group. The $95 \%$ confidence interval (CI) of the point estimate was used for significance testing. Stratified analyses were conducted initially to evaluate for confounding and test for effect modification (EM). The Mantel-Haenszel estimator was used to control confounding for a uniform OR, and the chi-square test for heterogeneity was used to test for EM. The Mantel-Haenszel extension test was used for analysis of trends. Finally, logistic regression analyses adjusted the OR for a priori-selected potential confounders. Adjusted ORs and 95\% CIs were calculated after controlling for categorical variables and prespecified confounders of gender, smoking (never, former, or current), occupational dust exposure, race (Hawaiian, Filipino, Japanese, White, and other), age (years), and body-mass index (BMI). Symptoms of cough or dry cough are known side effects from certain antihypertensive medications; hence, analyses for these symptoms were restricted to participants not taking these medications. Measures of central tendency were calculated on vital sign variables and Student's $t$-test of nondirectional hypotheses was performed for comparison of the unexposed and exposed groups. Demographic data of the groups were compared using chi-square or $t$-test analyses. All analyses employed a $5 \%$ probability of a Type I error $(\alpha=$ 0.05 ). Power analysis a priori determined the study's sample size to allow detection of $\geq 2.0$ epidemiological magnitude of effect. Data were analyzed with SPSS version 20.0 (SPSS, Chicago, IL).

\section{Results}

Study groups were comparable for nearly all demographic and health characteristics (Table 1). Significant differences between groups were identified in the percentage of native Hawaiians participants and average residency time.

Vog exposure was associated with substantially increased odds of self-reported cardiorespiratory and dermal symptoms (Table 2). Prevalence for daily cough, nocturnal dry cough, and cough with phlegm was significantly higher in the exposed group even when restricted to nonsmokers. The OR for SOB without exertion was three times higher in the vogexposed group with even higher magnitude for nonsmoking participants. Although prevalence of wheezing in the last year did not differ between groups, the symptom of wheezing most days and nights was significant with effect modification in exposed participants $<65$ years of age $(\mathrm{OR}=6.05$, CI: $1.67-$ 21.94; $P=0.015$ ). Upper airway, skin, and eye symptoms were over four times more likely to be reported by vog-exposed participants. All symptoms experienced while outdoors were associated with high exposure ORs. Significantly higher effect measures for sore or dry throat, wheezing day and night, and sinus congestion were associated with an increased distance from source $(P=0.03,0.02$, and 0.04 , resp.).

Medically-diagnosed hypertension was the only cardiorespiratory disease associated with vog exposure $(\mathrm{OR}=$ 1.92, CI: 1.01-3.67). Significant differences between groups were identified in vital sign measurements (Table 3). Elevated $\mathrm{BP}$ was associated with vog exposure in both OR and $t$ test analyses. The likelihood of having high BP ( $\geq 90$ diastolic or $\geq 140$ systolic) was doubled in exposed participants (adjusted OR = 2.32, CI: $1.30-4.14)$, with effect modification in elderly participants $(\mathrm{OR}=4.65, \mathrm{CI}$ : $1.82-11.91 ; P=$ $0.005)$. BP did not vary in relation to distance from source. A significantly higher mean systolic $\mathrm{BP}(+5.18 \mathrm{~mm} \mathrm{Hg})$ and mean diastolic BP $(+4.70 \mathrm{~mm} \mathrm{Hg})$ were identified in vogexposed participants. Significant exposure effects on BP were identified in nonsmokers, males, Filipinos, Whites, the elderly, and participants of normal weight. Nonsmokers exposed to $\geq 30 \mathrm{ppbv} \mathrm{SO}_{2}$ had significantly higher diastolic $\mathrm{BP}$ (+9.08 mm Hg; $P=0.01)$. Exposure effects were also detected for blood oxygen saturation. Average pulse measurements did not significantly differ between study groups; however, when analyses were restricted to nonsmokers and nonmedicated participants, exposed individuals averaged nearly 10 beats per minute (bpm) faster than their unexposed counterparts.

Half of all study participants perceived that the eruption since 2008 had affected their health. Not surprisingly, more participants from the exposed group (61\%) than from the unexposed group (37\%) expressed this belief. Exposed participants shared about daily experiences with the ongoing eruption and elevated vog, whereas unexposed residents described their experiences when vog came into their area or they visited an exposed area on the island. Health effects attributed to vog varied from minor nuisances to deterioration of health status. Participants without respiratory disease reported upper respiratory symptoms, irritability, low energy levels, body aches, sleep disturbances, and headaches. Chronic symptoms were throat irritation and a persistent cough that lasted for weeks. Participants with cardiorespiratory disease reported breathing difficulties ranging from exacerbations of chest tightness and breathlessness during everyday vog levels to distress only during high pollution events. These participants noted the importance of being compliant with self-care maintenance activities such as carrying emergency medications, using at-home nebulizer treatments and air conditioning in the car, and staying indoors.

Participants also noted aesthetic concerns, agricultural and animal husbandry effects, and financial impacts on their lives attributed to the increased eruption. They described occasionally experiencing the noxious sulfurous odor of vog, a metallic or acid-like taste, and declared the sky was no longer blue. Agricultural effects included kills of flower and vegetable crops (i.e., proteas, orchids) during high vog events, as well as overall reduced production in crops (i.e., coffee, avocados). Many participants reported nearly continuous visible leaf damage and showed the researcher examples in their garden or patios. In addition to a direct loss of income 
TABLE 1: Demographic and health characteristics of the study groups.

\begin{tabular}{|c|c|c|c|}
\hline Participant characteristics & Unexposed $(n=110)$ & Vog exposed $(n=110)$ & $P$ value \\
\hline Age, years $x(\mathrm{SD})$ & $59.0(19.5)$ & $56.4(17.3)$ & 0.31 \\
\hline Body-mass index, $x(\mathrm{SD})$ & $26.0(6.0)$ & $27.4(5.4)$ & 0.48 \\
\hline$\geq 25 n(\%)$ & $66(60)$ & $72(65)$ & \\
\hline Gender $n(\%)$ & & & 0.34 \\
\hline Female & $66(60)$ & $59(54)$ & \\
\hline Male & $44(40)$ & $51(46)$ & \\
\hline Ethnicity $n(\%)$ & & & 0.03 \\
\hline Filipino & $38(35)$ & $35(32)$ & \\
\hline White & $30(27)$ & $37(34)$ & \\
\hline Hawaiian & $11(10)$ & $23(21)$ & \\
\hline Japanese & $20(18)$ & $7(6)$ & \\
\hline Others & $11(10)$ & $8(7)$ & \\
\hline Residency, years $x(\mathrm{SD})$ & $39.4(24.1)$ & $32.0(21.1)$ & 0.02 \\
\hline Lifetime residency $n(\%)$ & $(45)$ & $(35)$ & 0.11 \\
\hline Employment $n(\%)$ & & & 0.35 \\
\hline Working & $40(36)$ & $45(42)$ & \\
\hline Unemployed & $11(10)$ & $20(15)$ & \\
\hline Retired & $53(48)$ & $37(36)$ & \\
\hline Disabled & $6(5)$ & $8(7)$ & \\
\hline Education, years $x(\mathrm{SD})$ & $12.62(2.7)$ & $12.65(2.4)$ & 0.93 \\
\hline \multicolumn{4}{|l|}{ Occupational exposures $n(\%)$} \\
\hline Sugarcane & $28(26)$ & $20(19)$ & 0.22 \\
\hline Macadamia Nuts & $16(15)$ & $28(26)$ & 0.05 \\
\hline Dust & $53(49)$ & $60(56)$ & 0.27 \\
\hline Age of home, years $x$ (SD) & $41.8(20.2)$ & $40.7(24.8)$ & 0.72 \\
\hline Plantation-style house $n(\%)$ & $32(29)$ & $34(31)$ & 0.77 \\
\hline Health insurance $n(\%)$ & $103(94)$ & $95(90)$ & 0.06 \\
\hline Smoking status $n(\%)$ & & & 0.64 \\
\hline Never & $53(49)$ & $48(44)$ & \\
\hline Former & $40(36)$ & $40(36)$ & \\
\hline Current & $17(16)$ & $22(20)$ & \\
\hline \multicolumn{4}{|l|}{ Medication usage $n(\%)$} \\
\hline Respiratory & $15(14)$ & $10(9)$ & 0.30 \\
\hline Antihypertensive & $48(44)$ & $49(45)$ & 0.84 \\
\hline Subjective view of health $n(\%)$ & & & 0.35 \\
\hline "Excellent" & $10(9)$ & $12(11)$ & \\
\hline "Very good" & $37(34)$ & $32(29)$ & \\
\hline "Average" & $56(51)$ & $50(46)$ & \\
\hline "Worse than average" & $5(4)$ & $11(10)$ & \\
\hline "Very poor" & $2(2)$ & $5(4)$ & \\
\hline Interviews English/Tagalog $n$ & $103 / 7$ & $103 / 7$ & 1.0 \\
\hline
\end{tabular}

Note. All participants were $\geq 20$ years with a minimum of 7 years residency in the study areas.

from cash crops, farmers and ranchers reported additional expenses such as replacement of fencing (sometimes hundreds of square miles), vitamin supplements for livestock, fertilizers for the soil, and replacement of new plants. Despite these adverse effects, some participants perceived a benefit from increased tourism on the island due to the attraction of Kìlauea's increased activity.

\section{Discussion}

This study at Kilauea volcano identified higher prevalence estimates and stronger magnitudes of cardiorespiratory effects associated with the increased volcanic activity and higher levels of pollution. Although $\mathrm{SO}_{2}$ emissions in this study were similar in total amount as during the 2004 study 
TABLE 2: Prevalence and exposure odds ratio of cardiorespiratory symptoms in adult residents of Hawai'i Island, USA.

\begin{tabular}{|c|c|c|c|c|}
\hline \multirow[b]{2}{*}{ Participant self-reported symptoms } & \multirow[b]{2}{*}{$\begin{array}{l}\text { Unexposed group } \\
P(\%)\end{array}$} & \multicolumn{3}{|c|}{ Vog exposed group } \\
\hline & & $P(\%)$ & $\begin{array}{c}\text { Crude OR } \\
(95 \% \text { CI })\end{array}$ & $\begin{array}{l}\text { Adjusted } \mathrm{OR}^{\mathrm{a}} \\
\quad(95 \% \mathrm{CI})\end{array}$ \\
\hline Chest pain & 20.0 & 29.4 & $1.66(0.89-3.10)$ & $1.61(0.85-3.08)$ \\
\hline $\begin{array}{l}\text { Cough }^{\mathrm{b}} \text { on most days for } 3 \text { consecutive or } \\
\text { more months/year }\end{array}$ & 15.4 & 56.8 & $7.23(3.52-14.84)$ & $8.18(3.81-17.58)$ \\
\hline Restricted to nonsmokers & 11.8 & 47.7 & $6.81(3.20-14.49)$ & $7.30(3.32-16.03)$ \\
\hline Dry cough at night for $>14$ days & 13.6 & 30.0 & $2.71(1.38-5.36)$ & $2.93(1.45-5.91)$ \\
\hline Restricted to nonsmokers & 14.0 & 27.3 & $2.31(1.09-4.89)$ & $2.56(1.17-5.57)$ \\
\hline Headaches often & 20.0 & 31.8 & $1.87(1.01-3.46)$ & $1.79(0.91-3.51)$ \\
\hline $\begin{array}{l}\text { Phlegm on most days for } 3 \text { consecutive or } \\
\text { more months/year }\end{array}$ & 14.5 & 39.1 & $3.77(1.96-7.25)$ & $3.61(1.83-7.11)$ \\
\hline Restricted to nonsmokers & 10.8 & 33.0 & $4.08(1.85-9.01)$ & $4.02(1.77-9.10)$ \\
\hline Cough and Phlegm combined & 10.0 & 34.5 & $4.75(2.27-9.92)$ & $4.78(2.21-10.32)$ \\
\hline Restricted to nonsmokers & 6.5 & 28.4 & $5.75(2.23-14.85)$ & $5.86(2.21-15.57)$ \\
\hline Rhinorrhea frequently & 12.7 & 35.5 & $3.77(1.90-7.46)$ & $4.66(2.26-9.64)$ \\
\hline Sinus/nasal congestion often & 12.7 & 36.7 & $3.98(2.01-7.87)$ & $4.75(2.32-9.76)$ \\
\hline SOB without exertion & 12.8 & 32.7 & $3.30(1.66-6.57)$ & $3.53(1.70-7.32)$ \\
\hline Restricted to nonsmokers & 12.2 & 33.0 & $4.03(1.82-8.91)$ & $4.33(1.88-10.01)$ \\
\hline Skin irritation & 7.3 & 26.4 & $4.52(1.96-10.42)$ & $5.12(2.15-12.20)$ \\
\hline Sore or dry throat frequently & 10.9 & 40.9 & $5.65(2.78-11.50)$ & $6.31(3.00-13.29)$ \\
\hline Wheeze within the last 12 months & 28.2 & 38.3 & $1.58(0.90-2.80)$ & $1.63(0.89-2.98)$ \\
\hline Wheeze most days or nights & 7.3 & 19.4 & $3.08(1.30-7.30)$ & $3.06(1.24-7.59)$ \\
\hline Wheeze during or after exercise & 9.3 & 17.8 & $2.12(0.93-4.80)$ & $2.07(0.88-4.87)$ \\
\hline \multicolumn{5}{|l|}{ Symptoms while outdoors: } \\
\hline Cough & 1.8 & 35.8 & $30.09(7.04-128.58)$ & $32.95(7.56-143.58)$ \\
\hline Eye irritation & 2.7 & 48.6 & $33.76(10.09-112.89)$ & $40.22(11.59-139.64)$ \\
\hline Rhinorrhea and sinus congestion & 0.9 & 30.0 & $46.29(6.20-345.72)$ & $53.11(7.0-401.93)$ \\
\hline Shortness of breath & 1.8 & 21.2 & $14.31(3.28-62.39)$ & $15.56(3.52-68.74)$ \\
\hline Wheezing & 1.8 & 19.6 & $13.06(2.98-57.27)$ & $14.95(3.30-67.70)$ \\
\hline
\end{tabular}

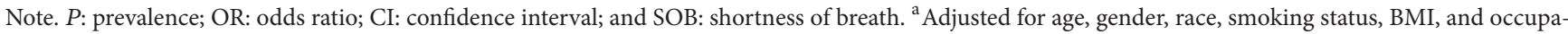
tional dust exposure. ${ }^{b}$ Nonmedicated: participants not taking medications with side effect of cough.

[12], the downwind communities experienced twofold the exposure due to the geographic location of the new summit vent relative to the island's wind flow patterns. The study further revealed an enhanced understanding of humanenvironmental interactions from both objective health data and subjective experiences of the eruption.

4.1. Physiological Findings. The study identified high prevalence and strong magnitudes of dermal, ocular, and cardiorespiratory effects from an average daily $\mathrm{SO}_{2}$ exposure of $49 \mathrm{ppbv}$ with hourly maximums up to $1,700 \mathrm{ppbv}$. Adverse physiological symptoms remained consistent with those identified during the initial study with lower exposure [12]. A vog-associated skin irritation was newly identified, yet previously observed in workers at Miyakejima island's volcano during periods of high $\mathrm{SO}_{2}$ [10]. No human studies to date have been conducted on dermal effects or the dermal exposure route of $\mathrm{SO}_{2}[27,28]$. Eye irritation was experienced by half of exposed participants, an increase from
$33 \%$ reported previously at Kïlauea [12]. A recent case series study in Honolulu during a high vog event identified signs of conjunctival injection with clear mucous discharge, along with symptoms of eye irritation, and the authors proposed the term vog-induced conjunctivitis [29]. It is validated that $\mathrm{SO}_{2}$ affects the mechanical functioning of the upper airways with minor ocular and nasal-pharyngeal effects [27, 30]. Most respiratory symptoms in the present study showed relatively higher prevalence and exposure odd ratios than previously identified, especially symptoms experienced while outdoors. Inhaled $\mathrm{SO}_{2}$ is mostly absorbed in the upper respiratory tract $(40 \%-90 \%)$ due to high water solubility [30]. Hence, the increased prevalence of respiratory symptoms relative to higher exposure is biologically plausible. Future studies in volcanic environments should include assessment of dermal exposure effects.

Further cardiorespiratory effects were revealed with the higher exposure, which included elevated BP parameters (systolic and diastolic) and SOB without exertion. The major 
TABLE 3: Student's $t$-test analysis of vital sign measurements of adult residents from Hawai'i Island, USA.

\begin{tabular}{|c|c|c|c|c|c|c|c|}
\hline \multirow{2}{*}{ Field-measured vital sign } & \multicolumn{3}{|c|}{ Unexposed group } & \multicolumn{3}{|c|}{ Vog exposed group } & \multirow[b]{2}{*}{$p_{(2)}$} \\
\hline & Mean & $\mathrm{SD}$ & $n$ & Mean & $\mathrm{SD}$ & $n$ & \\
\hline Pulse per minute (regular rhythm) & 76.81 & 12.45 & 106 & 76.29 & 14.30 & 99 & 0.78 \\
\hline Nonsmokers and nonmedicated & 75.33 & 12.54 & 12 & 84.90 & 17.54 & 20 & 0.11 \\
\hline Systolic blood pressure ( $\mathrm{mm} \mathrm{Hg}$ ) & 130.51 & 18.05 & 109 & 135.69 & 19.74 & 108 & 0.045 \\
\hline Nonsmokers & 130.41 & 18.18 & 92 & 137.31 & 19.03 & 87 & 0.01 \\
\hline Males & 129.32 & 16.35 & 44 & 136.72 & 18.78 & 50 & 0.04 \\
\hline Females & 131.32 & 19.20 & 65 & 134.79 & 20.65 & 58 & 0.34 \\
\hline Hawaiians & 134.18 & 25.15 & 11 & 135.04 & 22.55 & 23 & 0.92 \\
\hline Filipinos & 127.68 & 18.91 & 37 & 138.34 & 17.78 & 35 & 0.02 \\
\hline Whites & 128.80 & 14.44 & 30 & 138.40 & 19.24 & 35 & 0.03 \\
\hline Elderly $\geq 65$ years & 133.49 & 17.06 & 47 & 144.60 & 15.51 & 40 & 0.002 \\
\hline Nonsmokers with normal weight (BMI 18.5-24.9) & 130.00 & 18.03 & 41 & 138.15 & 17.37 & 41 & 0.04 \\
\hline Diastolic blood pressure (mm Hg) & 81.58 & 10.65 & 109 & 86.28 & 11.11 & 108 & 0.002 \\
\hline Nonsmokers & 80.72 & 10.61 & 92 & 85.82 & 10.80 & 87 & 0.002 \\
\hline Respirations per minute & 17.96 & 1.41 & 109 & 17.71 & 1.55 & 107 & 0.21 \\
\hline Blood oxygen concentration (Oximetry; \% $\mathrm{SpO}_{2}$ ) & 96.11 & 1.39 & 109 & 95.55 & 1.70 & 109 & 0.008 \\
\hline Nonsmokers & 96.10 & 1.22 & 92 & 95.45 & 1.72 & 87 & 0.004 \\
\hline
\end{tabular}

Note. SD: standard deviation; BMI: body-mass index; and mm Hg: millimeters of mercury.

risk factor for an acute cardiac event in persons $>50$ years of age is systolic $\mathrm{BP}>140 \mathrm{~mm} \mathrm{Hg}$ [26]. This parameter was exceeded by $60 \%$ of exposed participants, but by only $29 \%$ of the unexposed in this age range. Prevalence increased $12 \%$ since 2004 for this cardiovascular risk factor [12]. An elevated systolic BP in vog-exposed Filipinos was also previously identified [12] and observed in this study documenting a disparity needing further exploration. Therefore, in addition to routine screening, healthcare providers should educate on traditional cardiovascular risk factors and emphasize practical recommendations to reduce exposure [31]. Most interesting was the new finding of an exposure-associated decreased oxygen saturation, likely related to exposure of the $\mathrm{PM}_{2.5}$ component of vog rather than $\mathrm{SO}_{2}$. A study of 28 elders ( $>60 \mathrm{yrs}$ of age) found a significant inverse association between urban $\mathrm{PM}_{25}$ and oxygen saturation [32]. This study's findings, from an adult population in a volcanic environment, further support the hypothesis that cardiovascular functioning is affected by exposure to fine PM [31].

Most notable in this reassessment at Kilauea were vogassociated effects among nonsmokers for symptoms of daily cough, phlegm, dry cough, SOB without exertion, and objective measures of elevated BP parameters and lower oxygen saturation. These findings suggest an enhanced cardiorespiratory risk at the higher exposure levels among the general adult population, not just sensitive members. Still, participants with preexisting conditions perceived being most affected by vog, with challenges for disease management.

Downwind geographic areas were exposed to different volcanic pollutants relative to distance from emission source. This study is the first to identify geospatial differences in prevalence of respiratory ailments. Future health studies in volcanic environments should consider distance from source in epidemiological assessments. Studies have identified built environments (e.g., structure type) that can affect vogexposure risk and recommended interventions [16]. Hence, vulnerability is intertwined with volcanic phenomena in communities near active volcanoes.

4.2. Public Health Interventions. Over half of exposed participants perceived that their health was affected by Kilauea's eruption, yet they were motivated in self-care practices to live with this natural source of pollution. The high study participation rate reflected shared concerns in these island communities about health and environmental effects related to the ongoing eruption. The state of Hawai'i has used research evidence in the past to develop policy and prevention initiatives related to vog [33]. The Hawai'i Rural Health Association has been an advocate for exposed populations, working to increase the community's participation in their health. In addition to volcano monitoring, the Hawaiian Volcano Observatory of the USGS has been actively engaged with educating the public, and Hawai'i island's Civil Defense has developed emergency response plans for high vog events and other volcanic hazards. However, sustained multidisciplinary efforts are still needed to educate and protect these vulnerable communities from the current and future eruptions at Kilauea and other active volcanoes of Hawaii $i$.

On average, 50 volcanoes erupt each year [34]. The International Association of Volcanology and Chemistry of the Earth's Interior has a number of commissions working to reduce volcanic risk, including the multidisciplined International Volcanic Health Hazard Network [35]. Studies are now examining acute and residual effects of major eruptions and are leading to important public health interventions, disaster planning, and multidisciplinary efforts to enhance population health in volcanic areas around the world. Table 4 describes public health efforts that focus across levels of 


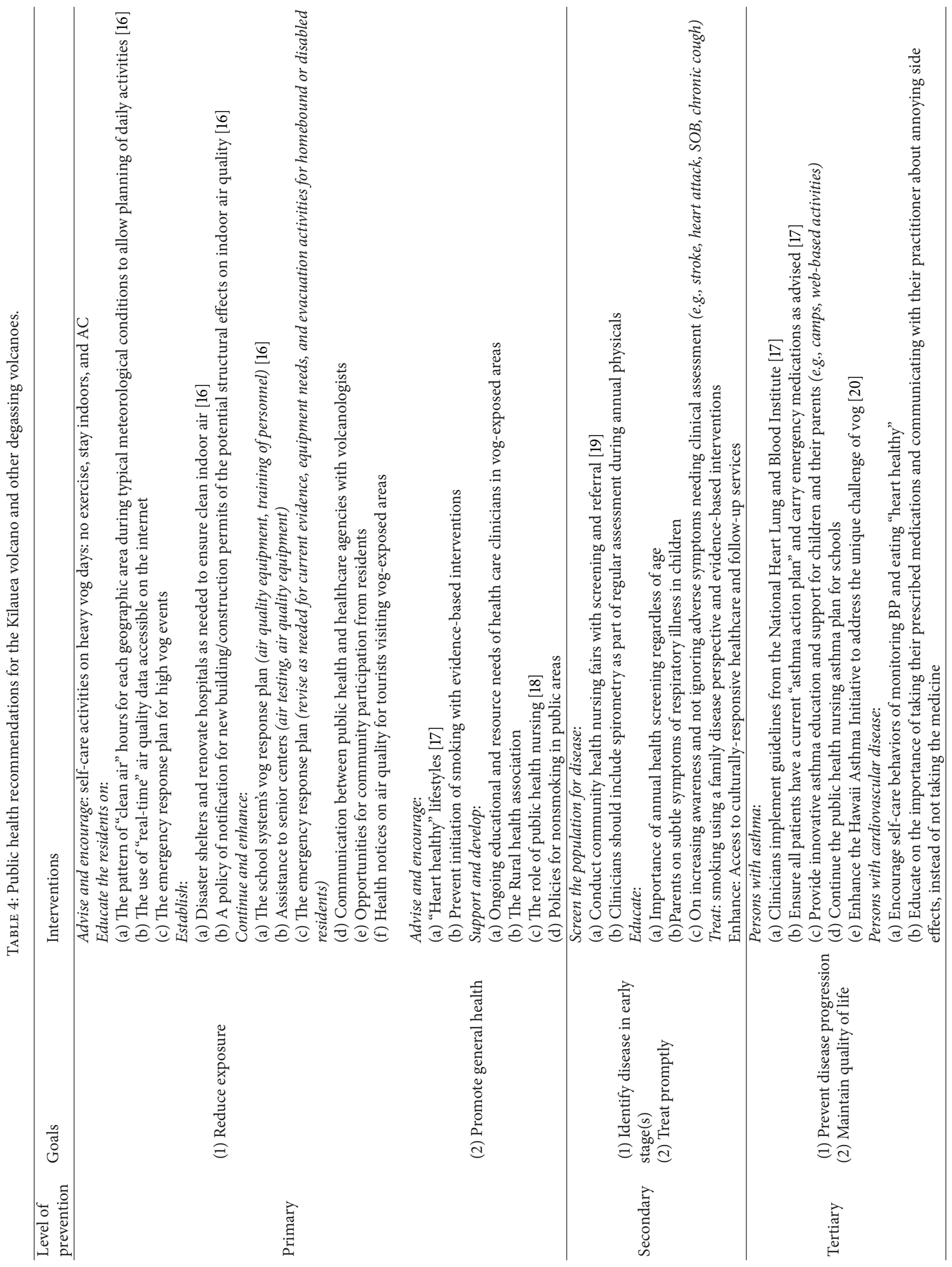


prevention and consider the vulnerable members of the population (i.e., children, elderly, and chronic disease). Knowledge gleaned from efforts at Killauea volcano is relevant to other communities challenged with volcanic activity and degassing.

4.3. Limitations. There are several considerations about this work that should be noted. First, the cross-sectional epidemiologic design was susceptible to selection bias, misclassification, and measured associations not causality. Vog has exposed the study area since 1983, yet migration out of the area is unknown. According to the recent 2010 US Decennial Census, both exposed and unexposed study areas experienced $+9 \%$ growths in population since 2000 [21]. However, this study found residency time was lower in the exposed group. Therefore, a "healthy survivor" effect could have underestimated prevalence in the exposed area. Misclassification through subject recall bias could also have affected prevalence estimates, though both study groups would be prone to this limitation. Second, Killauea offers a natural laboratory to study human-environmental interactions not a controlled environment. Concentrations and chemical composition of vog vary with changes in volcanic activity and island meteorology, resulting in inconsistent exposures. Thus, the health assessments occurred with differing concentrations of vog, from relatively low to high levels. Still, at some time over a 24 -hr period during the study, the exposed participants were exposed to vog. Third, the small sample size could not allow detection of small yet significant magnitudes of effect $(<2.0)$ for other cardiorespiratory diseases that could exist in the exposed population. Finally, potential confounding of these data must be considered. Even with restriction to prevent confounding effects and analyses to control confounding, there may have been an influence of unknown confounders on these estimates.

\section{Conclusions}

The magnitude of associated cardiorespiratory effects has increased in vog-exposed communities at the Kilauea volcano, Hawai'i. Many signs and symptoms of adverse biological responses have been detected in the exposed population that range from increased likelihood for experiencing upper respiratory reactions to more serious elevated cardiovascular risk factors. These findings are likely related to the higher volcanic air pollution experienced in downwind communities since the summit eruption began in 2008. Consequently, continuous epidemiologic surveillance, new screening programs, and enhanced evidence-based interventions for population health are recommended at Kilauea and other degassing volcanoes worldwide.

\section{Conflict of Interests}

The author declares no conflict of interests.

\section{Acknowledgments}

This study was funded by a small grant from the Sigma Theta Tau International Foundation. The author wishes to acknowledge the continued support for this program of research from the Orvis School of Nursing at the University of Nevada, Reno.

\section{References}

[1] C. Oppenheimer, Eruptions That Shook the World, Cambridge University Press, Cambridge, UK, 2011.

[2] C. Small and T. Naumann, "The global distribution of human population and recent volcanism," Environmental Hazards, vol. 3, no. 3-4, pp. 93-109, 2001.

[3] T. A. Mather, M. L. I. Witt, D. M. Pyle et al., "Halogens and trace metal emissions from the ongoing 2008 summit eruption of Killauea volcano, Hawai i'," Geochimica et Cosmochimica Acta, vol. 83, pp. 292-323, 2012.

[4] A. J. Sutton, T. Elias, J. W. Hendley II, and P. H. Stauffer, "Volcanic air pollution-A hazard in Hawaii," U.S. Geological Survey Fact Sheet 169-97, 2000.

[5] WHO, WHO Air Quality Guidelines for Particulate Matter, Ozone, Nitrogen Dioxide and Sulfur Dioxide, Global Update 2005, Summary of Risk Assessment, World Health Organization, Geneva, Switzerland, 2006.

[6] United States Environmental Protection Agency, "National Ambient Air Quality Standards, Sulfur dioxide," 2010, http:// www.epa.gov/air/criteria.html.

[7] B. Yager, "HOVE vog warning was issued," Hawaii TribuneHerald, 2008, http://www.hawaiitribuneherald.com/articles/ 2008/04/17/local_news/local03.prt.

[8] P. Delmelle, "Environmental impacts of tropospheric volcanic gas plumes," Geological Society Special Publication, vol. 213, pp. 381-399, 2003.

[9] M. Durand and J. Grattan, "Effects of volcanic air pollution on health," The Lancet, vol. 357, no. 9251, p. 164, 2001.

[10] A. Ishigami, Y. Kikuchi, S. Iwasawa et al., "Volcanic sulfur dioxide and acute respiratory symptoms on Miyakejima island," Occupational and Environmental Medicine, vol. 65, no. 10, pp. 701-707, 2008.

[11] R. Stephenson, G. Burr, M. Kawamoto, and B. Hills, "Exposures to volcanic emissions from the Hawaiian volcanoes: a NIOSH health hazard evaluation," Applied Occupational and Environmental Hygiene, vol. 6, no. 6, pp. 408-410, 1991.

[12] B. M. Longo, A. Rossignol, and J. B. Green, "Cardiorespiratory health effects associated with sulphurous volcanic air pollution," Public Health, vol. 122, no. 8, pp. 809-820, 2008.

[13] B. M. Longo, "The Kilauea Volcano adult health study," Nursing Research, vol. 58, no. 1, pp. 23-31, 2009.

[14] B. M. Longo, W. Yang, J. B. Green, F. L. Crosby, and V. L. Crosby, "Acute health effects associated with exposure to volcanic air pollution (VOG) from increased activity at kilauea volcano in 2008," Journal of Toxicology and Environmental Health A, vol. 73, no. 20, pp. 1370-1381, 2010.

[15] L. Rosen, "Hospital Surveillance for Vog Report," State of Hawaii Department of Health, 2009, http://hawaii.gov/health/ about/reports/Hospital_Surveillance_Vog_Report.pdf.

[16] B. M. Longo, W. Yang, J. B. Green, A. A. Longo, M. Harris, and R. Bibilone, "An indoor air quality assessment for vulnerable populations exposed to volcanic vog from Kilauea Volcano," Family and Community Health, vol. 33, no. 1, pp. 21-31, 2010.

[17] "NIH Heart, Lung, and Blood Institute," http://www.nhlbi.nih .gov/index.htm. 
[18] American Public Health Association, "Environmental health principles \& recommendations for public health nursing," 2005, http://www.apha.org/membergroups/newsletters/sectionnewsletters/public_nur/winter06/2550.htm.

[19] D. Lucky, B. Turner, M. Hall, S. Lefaver, and A. de Werk, "Blood pressure screenings through community nursing health fairs: motivating individuals to seek health care follow-up," Journal of Community Health Nursing, vol. 28, no. 3, pp. 119-129, 2011.

[20] Hawaii Department of Health, "Hawaii Asthma Initiative," http://hawaii.gov/health/family-child-health/chronic-disease/ asthma/coalition.html.

[21] "United States Geological SurveyHawaiian Volcano Observatory Daily Updates for Kilauea Volcano," 2012, http://volcano .wr.usgs.gov/kilaueastatus.php.

[22] Hawai'i State Department of Health, "Public notification: Air pollutant exceedence on Big Island, Clean Air Branch continual report," 2012, http://health.hawaii.gov/cab/notification-ofexceedance-of-a-national-ambient-air-quality-standard/.

[23] United States Decennial Census, 2010, http://www.census.gov/.

[24] "United States Department of Health and Human Services, NHANES, 1999-2000. Hyattsville, Maryland, National Center for Health Statistics, Centers for Disease Control and Prevention," 2003, http://www.cdc.gov/nchs/about/major/nhanes/ nhanes99-02.htm.

[25] B. G. Ferris, "Epidemiology standardization project (American Thoracic Society)," American Review of Respiratory Disease, vol. 118, no. 6, pp. 1-120, 1978.

[26] United States National Institute of Health, Seventh Report of the Joint National Committee on Prevention, Detection, Evaluation, and Treatment of High Blood Pressure (JNC7), NIH publication 04-5230, 2004.

[27] Agency for Toxic Substances \& Disease Registry, Toxicological Profile for Sulfur Dioxide, CAS 7446-09-5, US Department of Health and Human Services, Atlanta, Ga, USA, 1998.

[28] D. O. Johns and W. S. Linn, "A review of controlled human $\mathrm{SO}_{2}$ exposure studies contributing to the US EPA integrated science assessment for sulfur oxides," Inhalation Toxicology, vol. 23, no. 1, pp. 33-43, 2011.

[29] J. G. Camara and J. K. Lagunzad, "Ocular findings in volcanic fog induced conjunctivitis," Hawaii Medical Journal, vol. 70, no. 12, pp. 262-265, 2011.

[30] WHO, Sulfur Oxides and Suspended Particulate Matter, Environmental Health Criteria 8, World Health Organization, Geneva, Switzerland, 1979.

[31] R. D. Brook, S. Rajagopalan, C. A. Pope et al., "Particulate matter air pollution and cardiovascular disease: an update to the scientific statement from the american heart association," Circulation, vol. 121, no. 21, pp. 2331-2378, 2010.

[32] D. L. DeMeo, A. Zanobetti, A. A. Litonjua, B. A. Coull, J. Schwartz, and D. R. Gold, "Ambient air pollution and oxygen saturation," American Journal of Respiratory and Critical Care Medicine, vol. 170, no. 4, pp. 383-387, 2004.

[33] H. C. R. State of Hawaii, House of Representatives, 23rd Legislature, House Concurrent Resolution H.C.R. No. 141, H.D. 1, 2005, http://www.capitol.hawaii.gov/session2005/bills/hcr141_.htm.

[34] T. Simkin and L. Siebert, "Global Volcanism FAQs," Smithsonian Institution, Global Volcanism Program Digital Information Series, GVP-5, 2002, http://www.volcano.si.edu/education/questions/.

[35] “The International Volcanic Health Hazard Network," http:// www.ivhhn.org/. 


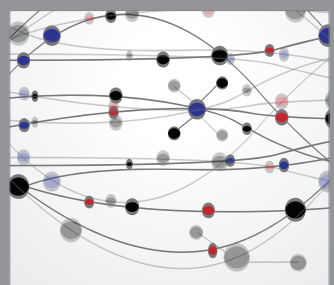

The Scientific World Journal
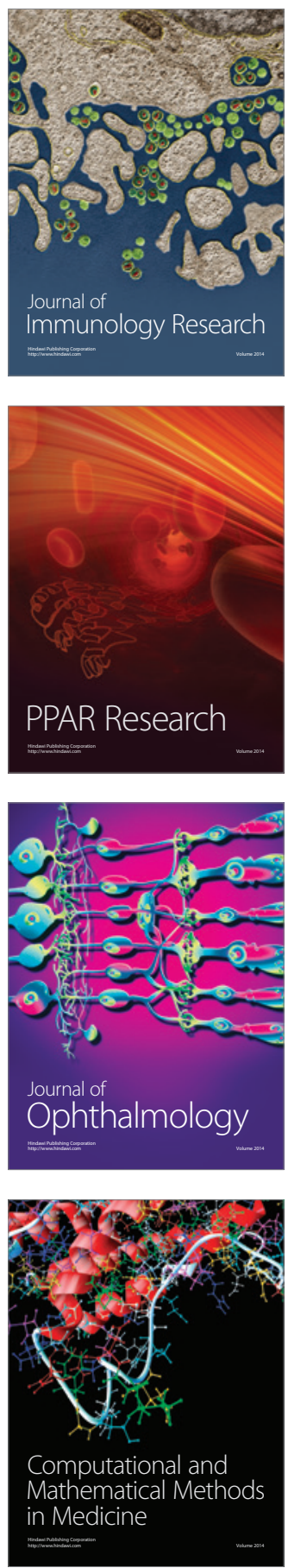

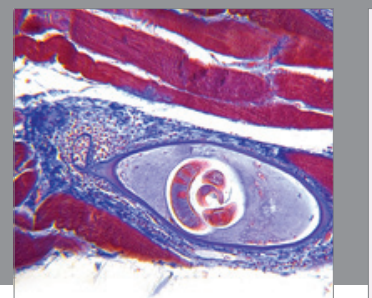

Gastroenterology

Research and Practice
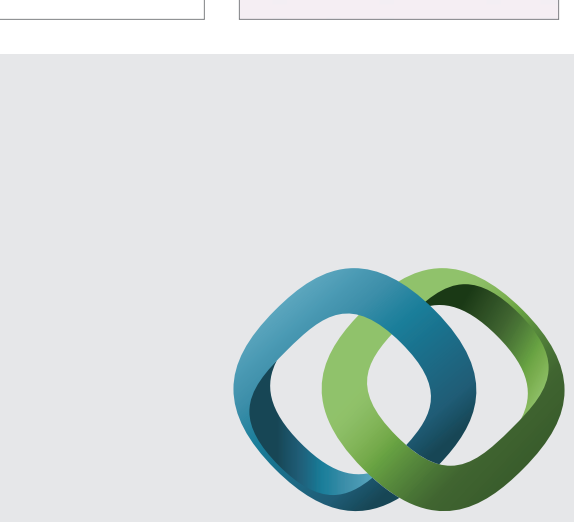

\section{Hindawi}

Submit your manuscripts at

http://www.hindawi.com
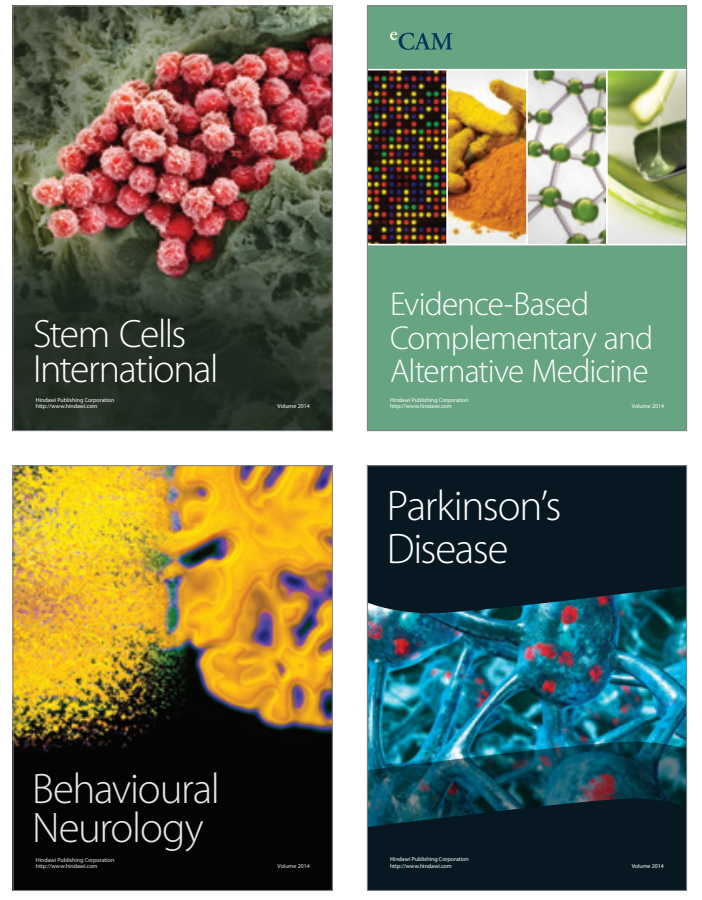
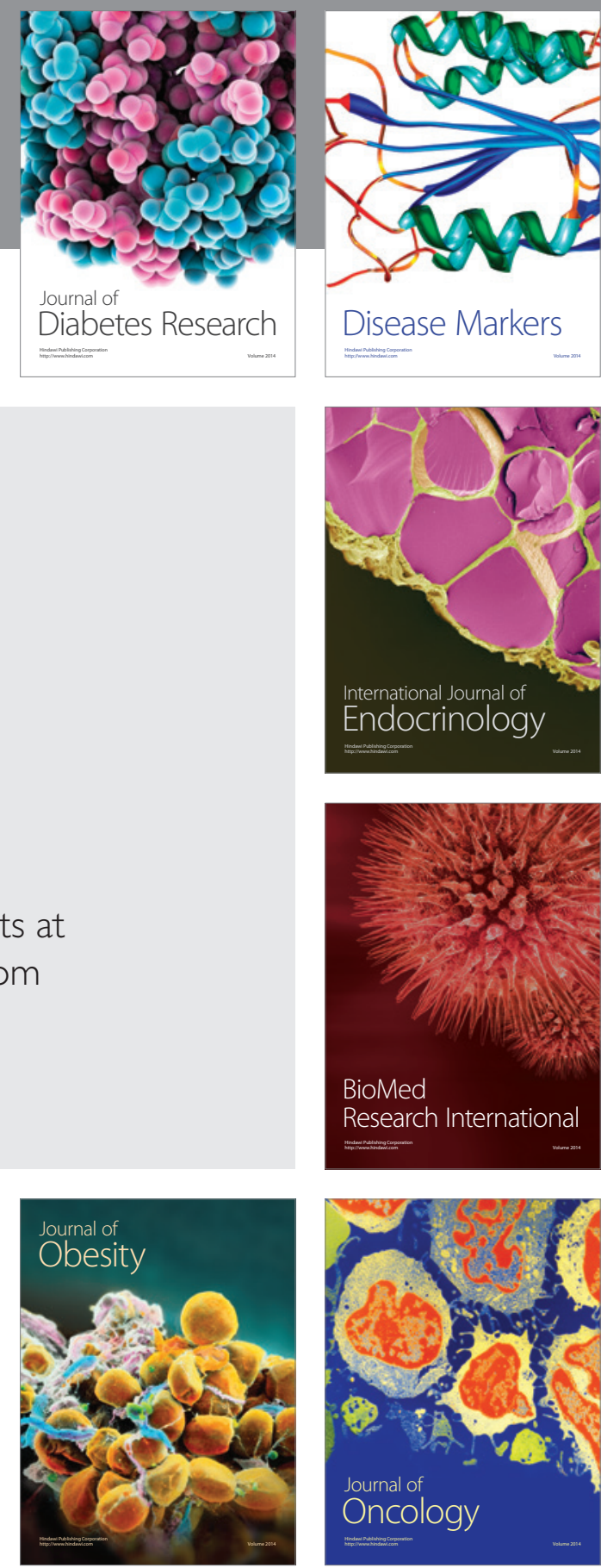

Disease Markers
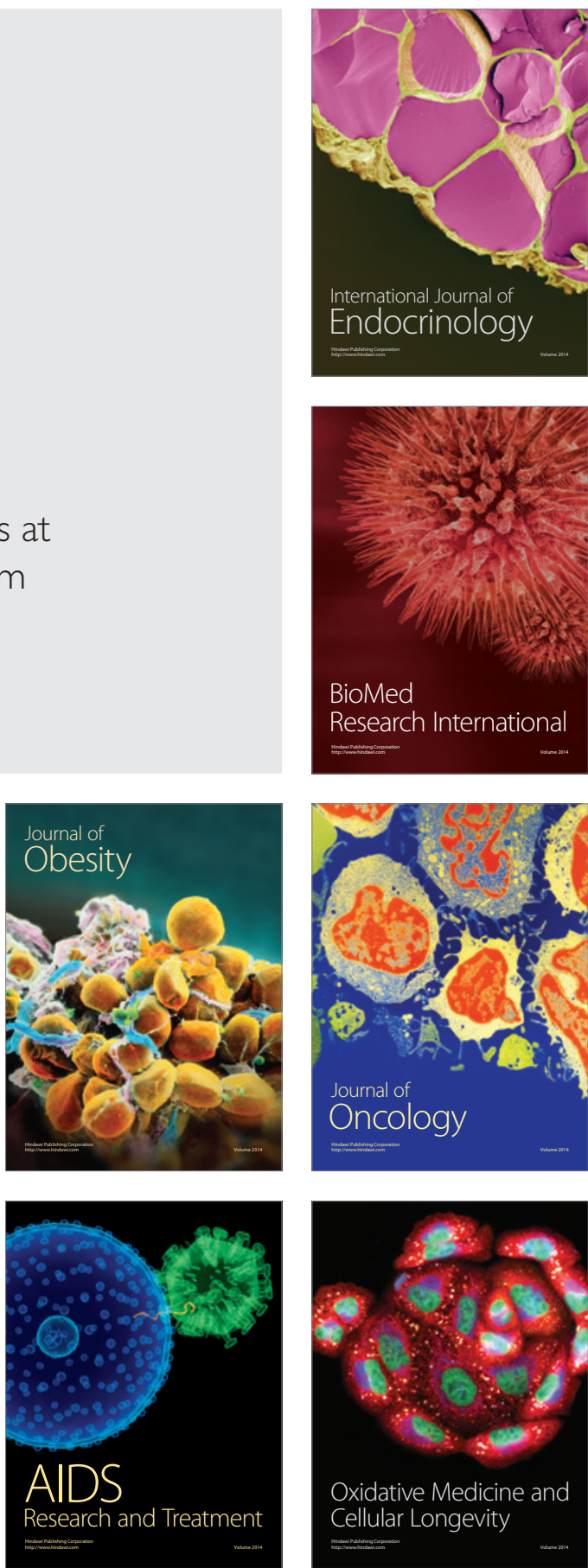